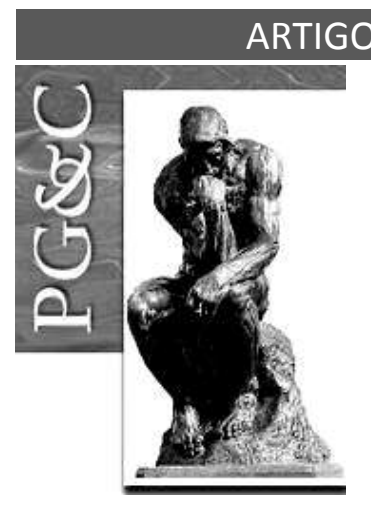

\title{
TRANSFERÊNCIA DE CONHECIMENTOS DE TRABALHADORES EM FASE DE APOSENTADORIA: UMA PRÁTICA EMPREENDEDORA?
}

\author{
Emanuele Canali Fossatti \\ Mestre em Administração pela Universidade de Passo Fundo, Brasil. \\ Professora da Universidade Regional Integrada do Alto Uruguai e das \\ Missões, Brasil. \\ E-mail: emanuelecfossatti@hotmail.com \\ Anelise Rebelato Mozzato \\ Doutora em Administração pela Universidade do Vale do Rio dos Sinos, \\ Brasil. Professora da Universidade de Passo Fundo, Brasil. \\ E-mail: anerebe@upf.br
}

\begin{abstract}
Resumo
O objetivo desta revisão de literatura é debater sobre a relevância em abordar a transferência de conhecimentos de trabalhadores em fase de aposentadoria como uma possível prática empreendedora, a qual pode resultar em satisfação pessoal e desenvolvimento organizacional. O cenário brasileiro atual aponta para o crescente envelhecimento populacional e destaca que a perda de conhecimentos decorrente do processo de aposentadoria pode representar uma ameaça para os grupos de trabalho e para as organizações. Apesar de os estudos internacionais avançarem crescentemente no que diz respeito à relação entre empreendedorismo e conhecimento, o debate nacional ainda é incipiente, especialmente na área das Ciências Sociais Aplicadas. Assim, torna-se pertinente incentivar estudos que abordem a transferência de conhecimentos de trabalhadores em fase de aposentadoria como uma prática intraempreendedora, uma vez que esta possibilita a constante criação de conhecimento e inovação nas organizações, além de minimizar a perda da memória organizacional.
\end{abstract}

Palavras-chave: Empreendedorismo. Intraempreendedorismo. Transferência de Conhecimento. Aposentadoria. Inovação.

\section{TRANSFER OF KNOWLEDGE OF WORKERS IN THE RETIREMENT PHASE: AN ENTREPRENEUR PRACTICE?}

\begin{abstract}
The purpose of this literature review is to discuss the relevance of approaching the knowledge transfer of workers in the retirement phase as a possible entrepreneurial practice, which can result in personal satisfaction and organizational development. The current Brazilian scenario points to the growing aging of the population and stresses that the loss of knowledge resulting from the retirement process can pose a threat to working groups and organizations. Although international studies are increasingly advancing with regard to the relationship between entrepreneurship and knowledge, the national debate is still incipient, especially in the area of Applied Social Sciences. Thus, it is pertinent to encourage studies that address the knowledge transfer of workers in the retirement phase as an intrapreneurial practice, since this enables the constant creation of knowledge and innovation in organizations, in addition to minimizing the loss of organizational memory.
\end{abstract}

Keywords: Entrepreneurship. Intrapreneurship. Transfer of Knowledge. Retirement. Innovation.

Perspectivas em Gestão \& Conhecimento, João Pessoa, v. 11, n. 1, p. 2-23, jan./abr. 2021. DOI: http://dx.doi.org/10.22478/ufpb.2236-417X.2021v11n1.47066

http://periodicos.ufpb.br/ojs2/index.php/pgc. ISSN: 2236-417X. Publicação sob Licença (cc) EY-Nc-ND 


\section{INTRODUÇÃO}

As organizações deparam-se com diversas transformações que ocorrem em múltiplas esferas e em ritmo acelerado, dentre as quais ressaltam-se a globalização dos mercados, os avanços tecnológicos e as tendências demográficas, destacando a importância e a necessidade de as organizações também transformarem-se constantemente e rapidamente (TAKEUCHI; NONAKA, 2008). As inovações tecnológicas estão transformando o ambiente de trabalho e reconfigurando as relações entre trabalhadores, seja por meio da substituição do trabalho físico por máquinas ou pela aprendizagem baseada na experiência em contraposição ao treinamento profissional individualizado (SANTOS; PEREIRA; LUCENA, 2019). Neste contexto, observa-se o cenário demográfico brasileiro que se apresenta em relação ao aumento da expectativa de vida e evolução do índice de envelhecimento da população. Segundo o Instituto Brasileiro de Geografia e Estatística - IBGE (2008), a combinação entre a redução dos níveis de fecundidade e de mortalidade no Brasil tem produzido modificações no padrão etário da população. $O$ formato triangular da pirâmide populacional abre espaço para uma pirâmide característica de uma sociedade em acelerado processo de envelhecimento, a qual é caracterizada pela redução da participação relativa de crianças e jovens, acompanhada do aumento proporcional de adultos e idosos.

Em contrapartida, observa-se a crescente presença de novas gerações nas organizações, as quais trazem consigo novos hábitos, valores e comportamentos (MUNARI et al., 2017). Equipes intergeracionais são determinantes de um novo ambiente (COLET; MOZZATO; BITENCOURT, 2017) e de um modo de trabalho que combina/contrasta experiência e dinamismo/velocidade na ação com inexperiência e cautela na decisão (CAMARANO, 2001; SILVA; WETZEL; SZUCHMACHER, 2008; VANZELLA; LIMA NETO; DA SILVA, 2011). Assim, um dos desafios para o qual as organizações nem sempre estão preparadas, consiste em preparar os trabalhadores em fase de aposentadoria para transferirem seus conhecimentos para as gerações subsequentes, uma vez que indivíduos de diferentes gerações possuem conhecimentos diferenciados e os compartilham em momentos diversos (SOUTO, 2014; GERPOTT; WILLENBROCK; VOELPEL, 2017).

Ressalta-se que o conhecimento dos trabalhadores em fase de aposentadoria apresenta o diferencial de ter sido construído por um longo período de tempo por meio de interações, relacionamentos e projetos que podem ser fundamentais para a inovação nas organizações, e ainda, são difíceis de reconstruir (SOUTO, 2014). Para gerar inovação é necessário que exista uma combinação entre conhecimento, criatividade e empreendedorismo. O conhecimento oportuniza o desenvolvimento de uma nova ideia que, associada a criatividade, provoca a inovação e o empreendedorismo nas organizações (LOPES et al., 2016). Neto, Perin e Ferreira (2019) observam que a competitividade tem conduzido as organizações a buscar diversas fontes de inovação, com destaque para transferência de conhecimento.

Borges et al. (2016) observam que ainda são poucos os estudos voltados ao empreendedorismo que abordam a esfera da aprendizagem, a exemplo de Hamilton (2011) e Zahra (2012). Segundo os autores, a aprendizagem, dentre outras temáticas pouco abordadas em estudos na área de empreendedorismo, indica a tentativa dos pesquisadores em apreender uma diversidade de perspectivas que se associam ao empreendedorismo, colaborando para a formação de um campo de estudos dinâmico, plural e multifacetado. Do mesmo modo, Martens et al. (2016) apontam como agenda futura de pesquisas na área de empreendedorismo alguns temas emergentes, porém pouco explorados nos últimos anos, os quais se relacionam ao crescimento, à aprendizagem, ao conhecimento e aos recursos e capacidades.

Perspectivas em Gestão \& Conhecimento, João Pessoa, v. 11, n. 1, p. 2-23, jan./abr. 2021. 
Ao buscar conhecer o campo de debate que aborda, em conjunto, o empreendedorismo e o conhecimento no período e 2013 a 2018, observa-se crescimento na quantidade de estudos internacionais que fazem tal relação, porém, o debate nacional ainda é incipiente, especialmente na área das Ciências Sociais Aplicadas. Dos 3.252 estudos localizados nas bases de dados Sage, Scielo, Scopus e Spell, 1.937 estudos correspondem à área das Ciências Sociais Aplicadas e destes apenas 51 são nacionais, o que corresponde a apenas 2,6\% dos estudos na respectiva área e 1,5\% do total de estudos. Para realizar a busca citada, optouse por procurar nos títulos, resumos e palavras chaves dos documentos a relação entre empreendedorismo e conhecimento, na língua portuguesa e inglesa, a fim de traçar um panorama geral do campo de pesquisa. Porém, estes dados não contemplam uma análise aprofundada que aponte de que forma a relação entre o conhecimento e o empreendedorismo está sendo abordada em tais estudos.

A relação entre empreendedorismo e conhecimento é pertinente, uma vez que o conhecimento é visto como uma das alternativas para proporcionar o desenvolvimento organizacional, além de ser considerado uma das formas de as organizações permanecerem e se destacarem onde estão inseridas (JESUS; MOURÃO, 2012; GERPOTT; WILLENBROCK; VOELPEL, 2017). Na perspectiva de Nonaka e Takeuchi (2003), o conhecimento organizacional pode ser compreendido como a capacidade de uma organização criar conhecimento, difundi-lo e incorporá-lo a suas práticas. Deste modo, a transferência de conhecimentos entre os trabalhadores é um elemento fundamental da aprendizagem organizacional (AO), uma vez que para que o conhecimento organizacional não se perca, este precisa ser transferido entre indivíduos e áreas (MURRAY; PEYREFITTE, 2007; KANG; KIM, 2010). A transferência de conhecimentos é associada com a aplicação de conhecimentos ou habilidades para solucionar problemas, melhorar práticas de gestão, ampliar a produtividade, capacitar pessoas e contribuir para o melhor desempenho das organizações (ARAÚJO; POPADIUK, 2015).

Estudos anteriores afirmam que a perda de conhecimentos resultante da rotatividade induzida pela aposentadoria pode representar uma ameaça para as organizações, apontando os grupos de trabalho como uma possível solução, visto que o legado de conhecimentos e experiências dos trabalhadores em fase de aposentadoria ou aposentados podem permanecer nas organizações se forem incorporados em processos grupais (ASHWORTH, 2006; CHIGADA; NGULUBE, 2016). Porém, Bleich et al. (2015), ao examinarem as práticas organizacionais atuais, afirmam que existem poucos exemplos de abordagens intencionais para incentivar a transferência de conhecimentos de trabalhadores em fase de aposentadoria por parte das organizações.

Assim, esta revisão de literatura tem como objetivo debater sobre a relevância em abordar a transferência de conhecimento de trabalhadores em fase de aposentadoria como uma possível prática empreendedora, que pode resultar em satisfação pessoal e desenvolvimento organizacional. Para isso, este texto será dividido em cinco partes: introdução à temática - já apresentada -; reflexões sobre as implicações do processo de aposentadoria nas organizações; reflexões sobre a transferência de conhecimento organizacional; reflexões sobre a possibilidade de empreender por meio da transferência de conhecimentos; e, por fim, são apresentadas as considerações finais, as quais buscam instigar o leitor em relação à transferência de conhecimentos por parte de trabalhadores em fase de aposentadoria como uma possível prática empreendedora.

\section{PROCESSO DE APOSENTADORIA: IMPLICAÇÕES PARA AS PESSOAS E PARA AS ORGANIZAÇÕES}

A criação da aposentadoria está atrelada às modificações sociais e organizacionais que ocorreram a partir do século XIX, tais como as exigências do mercado de trabalho quanto à sua

Perspectivas em Gestão \& Conhecimento, João Pessoa, v. 11, n. 1, p. 2-23, jan./abr. 2021. 
necessidade de renovação de pessoas, estabelecendo assim critérios para inserção, permanência e afastamento dos indivíduos em suas atividades laborais (ANTUNES; SOARES; SILVA, 2015). Por outro lado, observa-se que outros sentidos, além do econômico e instrumental, são produzidos sobre a aposentadoria, os quais dizem respeito ao fato de que o trabalho não é mais vivenciado somente em seus aspectos restritivos, ligados às condições de trabalho, mas sim é considerado em suas demais esferas (MACÊDO; BENDASSOLLI; TORRES, 2017). A visão tradicional da aposentadoria percebida como um evento de retirada definitiva do trabalho tem dado lugar a aposentadoria como um processo de múltiplas formas, cada vez menos associada à velhice ou a uma vida voltada para o ócio e o lazer (FRANÇA, 1999; EKERDT, 2010; SHULTZ; HENKENS, 2010; FRANÇA; STEPANSKY, 2016).

Observa-se a existência de um consenso nos estudos científicos de que a vivência da aposentadoria provoca profundas modificações na vida dos indivíduos, visto que, para estes, é necessário reorganizar-se no âmbito pessoal, familiar e social (ANTUNES; SOARES; SILVA, 2015). O processo de aposentadoria faz com que o trabalhador se depare com diversas perdas que englobam fatores econômicos e subjetivos, tais como os benefícios e status oferecidos pelo cargo ocupado, planos de saúde, adicionais de lucro, viagens, poder de decisão, senso de pertencimento à organização ou grupos de trabalho, entre outros (FRANÇA, 2002). Assim, as reações frente a aposentadoria podem ser diversas: expressões de alívio, apreensão, sentimento de perda, temores ligados a inutilidade, isolamento, dificuldades financeiras e desatualização, entre outros. Porém, observa-se que a transição que ocorre na aposentadoria pode ser facilitada quando se promovem ações no contexto organizacional, enquanto o indivíduo ainda executa suas atividades laborais (ZANELLI, 2000).

Como consequência, a aposentadoria repercute em diferentes espaços e processos laborais, pois o desligamento de um indivíduo é capaz também de gerar intensas modificações na forma como uma organização compreende e institui suas metodologias, políticas e práticas (ANTUNES; SOARES; SILVA, 2015). Antunes, Soares e Silva $(2015$, p. 2) afirmam que a aposentadoria pode ser vista como uma ameaça às organizações, pois "com o rompimento do vínculo empregatício, é possível que ocorra a perda de corpo profissional altamente qualificado e especializado, e, consequentemente, a perda de conhecimento". Deste modo, Kim e Ko (2014) ressaltam que as organizações deveriam refletir a respeito da transferência de conhecimento entre os trabalhadores em fase de aposentadoria para os demais, antes que o processo de aposentadoria seja finalizado de fato.

Ressalta-se que os trabalhadores em fase de aposentadoria possuem mais do que habilidades rudimentares e know-how de rotina sobre processos comuns. Eles também têm conhecimento advindo do conhecimento tácito, isto é, do conhecimento pessoal que é incorporado na experiência individual e que envolve fatores intangíveis. À medida que os trabalhadores em fase de aposentadoria desligam-se de uma organização, eles levam consigo uma riqueza de experiências e conhecimentos acumulado ao longo de anos (SUMBAL; TSUI; LEE, 2015). Uma vez que o conhecimento tácito é mais difícil de ser compartilhado (BLEICH et al., 2015), faz-se necessário que as organizações busquem caminhos para manter os trabalhadores aposentados e com know-how nas organizações, assim como incentivem a transferência de conhecimento destes com os demais (DAWOUD et al., 2014; CAHA et al., 2017; THÜRMER; YEDYENYOVA; SPIEB, 2017).

Diante das rápidas mudanças e complexidade do mundo do trabalho, bem como da busca pela sobrevivência no mercado competitivo, é essencial que a lideranças busquem alternativas na própria equipe de trabalho, por meio do incentivo do perfil empreendedor, abrangendo a criatividade, inovação e o conhecimento como matéria prima para o desenvolvimento organizacional (LOPES et al., 2016). Ressalta-se a importância de que sejam criadas ações voltadas à aprendizagem, de modo que os trabalhadores possam aprender também com os conhecimentos e experiências daqueles que estão se desvinculando do

Perspectivas em Gestão \& Conhecimento, João Pessoa, v. 11, n. 1, p. 2-23, jan./abr. 2021. 
trabalho. Deste modo, considera-se a diversidade de conhecimentos que emerge a partir da história de cada trabalhador no decorrer de sua trajetória organizacional, possibilitando a integração e a transferência de saberes entre as pessoas (ANTUNES; SOARES; SILVA, 2015).

As organizações também se beneficiam desta transferência, uma vez que por meio do compartilhamento, é possível de certa forma manter as experiências e os conhecimentos dos trabalhadores em fase de aposentadoria nas organizações (THÜRMER; YEDYENYOVA; SPIEB, 2017). Atualmente, um dos maiores desafios enfrentado pelas organizações está relacionado justamente à inovação e à sustentação de boas ideias. Assim, ressalta-se o impacto que o investimento em conhecimento, criatividade e inovação proporcionam para as organizações (BONINI; SBRAGIA, 2011).

Mansour e Tremblay (2019) apontam que a transferência de conhecimento leva ao sucesso de uma organização, visto que o conhecimento tem sido considerado como o recurso mais estrategicamente significativo das organizações. Os respectivos autores afirmam que quando os trabalhadores mais velhos têm a oportunidade de usar suas habilidades e experiências e transferi-los para a geração mais jovem, eles tendem a ficar mais satisfeitos e seu nível de comprometimento com a organização é maior.

Neste contexto, Munari et al. (2017, p.3) ressaltam o papel das organizações no sentido de utilizar todas as ferramentas e habilidades que a realização de projetos que estimulem o compartilhamento de experiências entre profissionais de diferentes gerações oferece, visto que este "pode ser um caminho para o alcance da formação de líderes eficazes pautados por comportamentos éticos e decisões inovadoras". Além disso, certas práticas de gestão de pessoas (GP), que são percebidas como favoráveis pelos trabalhadores, promovem o comportamento de compartilhamento de conhecimentos, como bem pontuam Kim e Ko (2014). Segundo Rau e Adams (2013), a área de GP preocupa-se com o âmbito organizacional da aposentadoria, abordando a necessidade do planejamento dos trabalhadores, 0 planejamento para a sucessão, o recrutamento para a volta ao mercado de trabalho, a questão geracional e a transferência de conhecimentos, entre outras, buscando relacionar as questões vinculadas a aposentadoria à estratégia organizacional.

Deste modo, uma vez que o conhecimento é criado apenas pelos indivíduos, faz-se necessário que as organizações apoiem, incentivem e estimulem as atividades criadoras de conhecimento, bem como a transferência de conhecimentos. A criação do conhecimento organizacional é entendida como um processo que amplifica o conhecimento e o cristaliza no nível do grupo por meio do diálogo, discussões e compartilhamento de experiências (TAKEUCHI; NONAKA, 2008). Sanakam (2014) aponta que os trabalhadores em fase de aposentadoria muitas vezes atuam como mentores ou supervisores de trabalhadores mais jovens, a fim de aprimorar seu desempenho e minimizar as possíveis perdas de talentos e memória da organização em que atuam. Segundo Takeuchi e Nonaka (2008, p. 7), o conhecimento pode ser visto como uma resposta para enfrentar o ambiente de mudanças, uma vez que "a característica exclusiva do conhecimento reside no fato de que este se torna obsoleto tão logo é criado". Neste contexto, o crescente envelhecimento dos trabalhadores é um ponto crítico para a área de GP (ASHWORTH, 2006), visto que pode resultar na perda de conhecimento organizacional (FRANÇA; CARNEIRO, 2009). Uma das possibilidades de minimização desta situação se dá por meio da realização de projetos que estimulem o compartilhamento de experiências entre profissionais de diferentes gerações, envolvendo uma relação mútua e respeitosa que pode oportunizar aos trabalhadores em fase de aposentadoria o espaço para contarem suas histórias e oferecerem seus conselhos e, aos trabalhadores mais jovens, o compartilhamento de seus sonhos, dificuldades e desafios (MUNARI et al., 2017).

Ressalta-se que por meio da troca de conhecimentos é possível alcançar resultados mais efetivos para as organizações e para os trabalhadores (SANTOS; VALENTIM, 2014). Lopes et al. (2016) afirmam que, diante da competitividade no mercado é fundamental que as 
organizações mantenham atitudes empreendedoras, buscando melhorias por meio da criatividade, da inovação e do conhecimento.

\section{TRANSFERÊNCIA DE CONHECIMENTO ORGANIZACIONAL}

O campo da gestão do conhecimento (GC) surgiu nos anos 1990 e é compreendido por diferentes perspectivas e abordagens, visto que não há um único conceito capaz de englobar todas as facetas do conhecimento e sua complexidade (ZIMMER; LEIS, 2011). Ressalta-se que ainda não existe um consenso conceitual entre os teóricos interessados pela GC, visto que existe na literatura um grande número de abordagens e tentativas de definição (RIBEIRO et al., 2017). No Brasil, a publicação da obra "Criação de conhecimento na empresa: como as empresas japonesas geram a dinâmica da inovação" de Nonaka e Takeuchi, em 1997, despertou o interesse na temática, concebendo o conhecimento como um recurso central na inovação (CASTRO; GUIMARÃES; DINIZ, 2013).

Segundo Nonaka e Takeuchi (2003, p. 1), o conhecimento organizacional pode ser compreendido como "a capacidade de uma empresa de criar novo conhecimento, difundi-lo na organização como um todo e incorporá-lo a produtos, serviços e sistemas". Neste sentido, a transferência de conhecimentos contribui para a geração de novas ideias com o objetivo de desenvolver novos produtos, por meio do estímulo e da combinação de conhecimentos já existentes, com aqueles que foram adquiridos (COHEN; LEVINTHAL, 1990; VAN WIJK; JANSEN; LYLES, 2008). Lyles e Easterby-Smith (2003) enfatizam que até o ano de 2001, a criação e a transferência de conhecimentos eram os temas mais pesquisados por especialistas em AO no exterior. Porém, não houve ampla correspondência desta temática com a produção nacional. Os autores afirmam que a menor incidência de termos como memória organizacional e aprendizagem de grupo no âmbito científico nacional poderia estar relacionada com a baixa quantidade de estudos voltados à transferência de conhecimentos, ressaltando a importância de pesquisas na área.

Chauvet e Guiot (2002) observam que, além da transferência de conhecimentos, a capacidade absortiva também foi utilizada para explicar eventos organizacionais, uma vez que as organizações dependem do conhecimento adquirido para facilitar o desenvolvimento de suas capacidades. Segundo os referidos autores, a capacidade absortiva em conjunto com a propensão à transferência de conhecimento pode otimizar a criação de novos conhecimentos, o desenvolvimento da inovação e a flexibilidade estratégica. Neste contexto, Engelman et al. (2017) observam que os recursos intangíveis e a capacidade de absorver e utilizar o conhecimento externo impacta positivamente em processos de inovação nas organizações.

Segundo Takeuchi e Nonaka (2008) o conhecimento é formado por dois elementos complementares: conhecimento explícito e tácito. De acordo com os autores, o conhecimento explícito pode ser expresso por meio das palavras e compartilhado na forma de dados e recursos visuais, entre outros. É um conhecimento que pode ser facilmente transmitido aos indivíduos, enquanto, por outro lado, o conhecimento tácito não é facilmente visível e explicável, pois está profundamente enraizado nas ações e nas experiências dos indivíduos, envolvendo assim seus ideais, valores e emoções. O conhecimento tácito se manifesta em duas dimensões chamadas de cognitiva e técnica. Segundo Takeuchi e Nonaka (2008), a primeira delas é permeada por crenças, percepções, ideais, valores, emoções e modelos mentais inseridos no indivíduo; a segunda perspectiva engloba as habilidades informais, muitas vezes apreendidas no termo know-how, as quais são apreendidas por meio da experiência e difíceis de serem explicadas em palavras. Souto (2014) afirma que a dimensão tácita do conhecimento só pode ser adequadamente compartilhada em interações sociais, onde as conversas face-to-face são essenciais para que os aspectos relacionais como a confiança e a construção de proximidade permitam a reflexão, favorecendo o acesso a

Perspectivas em Gestão \& Conhecimento, João Pessoa, v. 11, n. 1, p. 2-23, jan./abr. 2021. 
conhecimento. Ressalta-se que o conhecimento é explícito e tácito e a forma que as organizações encontram para criar novos conhecimentos é convertendo-os de um tipo para o outro por meio de uma espiral, chamada espiral Seci (TAKEUCHI; NONAKA, 2008). Knoetze (2019) observam que a transferência de conhecimento tácito e explícito constitui um componente crucial para a continuidade organizacional.

Fazem parte desta espiral quatro modos de conversão de conhecimento: socialização, externalização, combinação e internalização (TAKEUCHI; NONAKA, 2008). De acordo com os autores, na primeira etapa, na fase de socialização, o conhecimento tácito é compartilhado de indivíduo para indivíduo, para posteriormente; na fase de externalização, o conhecimento tácito deve ser compartilhado do indivíduo para o grupo, tornando-o explícito; na fase de combinação, o conhecimento explícito é compartilhado do grupo para a organização; por fim, na fase de internalização, o conhecimento explícito precisa ser compartilhado da organização para o indivíduo, tornando-o tácito novamente e criando um novo conhecimento. A interação entre o conhecimento tácito e explícito, segundo os autores, é contínua, dinâmica e simultânea, assim como o conhecimento é amplificado à medida que passa para os níveis ontológicos, do indivíduo para o grupo e, então, para a organização.

Nonaka e Takeuchi $(2003$, p.10) afirmam que "o conhecimento deve ser construído por si mesmo, por meio de uma interação intensiva entre os membros da organização". Os autores afirmam que o conhecimento pode ser amplificado em nível de grupo por meio de discussões, compartilhamento de experiências e observação. A etapa de socialização começa pelo desenvolvimento de um campo de interação, o qual facilita o compartilhamento de experiências e modelos mentais. A externalização é provocada pelo diálogo ou pela reflexão coletiva, nos quais o emprego de uma metáfora ou analogia significativa ajuda os membros da equipe a articularem o conhecimento tácito. A combinação é provocada pelo agrupamento do conhecimento recém-criado e do conhecimento já existente proveniente da organização em uma rede, cristalizando-os assim em um novo produto, serviço ou sistema. Por fim, o aprender fazendo provoca a internalização e a consequente criação de um novo conhecimento. A Figura 1 apresenta as características deste processo.

Figura 1 - Espiral Seci

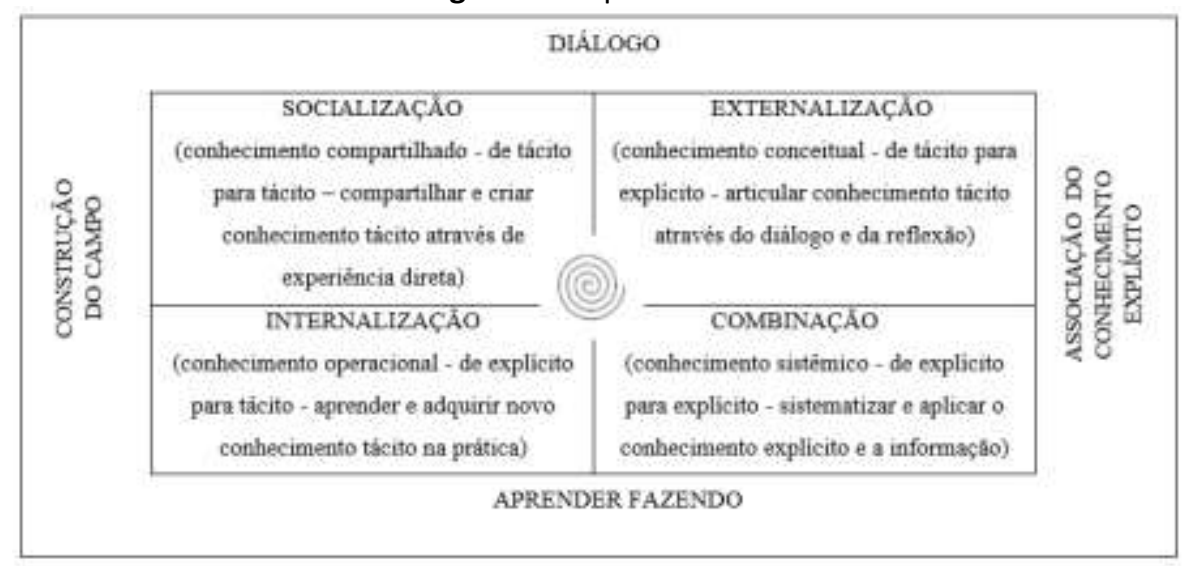

Fonte: Adaptado de Takeuchi e Nonaka (2008).

Nonaka e Takeuchi (2003) afirmam ainda que existem cinco fases de criação do conhecimento organizacional. A primeira delas, chamada de compartilhamento de conhecimento tácito, relaciona-se ao fato de que o conhecimento não pode ser transmitido de maneira simples, pois é adquirido por meio da experiência. Assim, para alcançar tal compartilhamento, é necessário um campo no qual os indivíduos possam interagir uns com os outros e compartilhar experiências. Na segunda delas, chamada de criação de conceitos, o

Perspectivas em Gestão \& Conhecimento, João Pessoa, v. 11, n. 1, p. 2-23, jan./abr. 2021. 
modelo mental tácito compartilhado é verbalizado em palavras e frases e, finalmente, cristalizado em conceitos explícitos. Na terceira fase - justificação de conceitos - os novos conceitos precisam ser justificados, a fim de determinar seu valor para a organização e para sociedade. Na quarta fase - construção de um arquétipo - um conceito justificável é transformado em algo tangível, combinando-se o conhecimento explícito recém-criado e o conhecimento explícito existente. Na última fase - difusão interativa do conhecimento - o novo conceito que foi criado, justificado e transformado em modelo passa para um novo ciclo de criação do conhecimento em um nível ontológico diferente.

Takeuchi e Nonaka (2008) reforçam que a espiral do conhecimento é impulsionada por algumas condições organizacionais, reforçando a ideia de que a cultura organizacional não está desvinculada dos processos de criação e transferência de conhecimentos, uma vez que também o comportamento dos trabalhadores perpassa esta esfera (DAVENPORT; PRUSCAK, 2003; CALO, 2008). Antunes, Soares e Silva (2015) ressaltam que as ações orientadas à aprendizagem e transferência de conhecimento podem trazer importantes contribuições para organização, no que diz respeito à valorização do trabalhador e a transferência de conhecimentos individuais que podem ser apreendidos no nível organizacional. Portanto, estudos sugerem que as organizações devem dar prioridade ao compartilhamento de conhecimentos da equipe e considerar a inclusão e adoção de conhecimentos em seus objetivos de negócios, a fim de desenvolver as pessoas e aprimorar as capacidades operacionais (CHIRAWATTANAKIJ; RACTHAM, 2015). Embora o empreendedorismo dependa de fatores em diferentes níveis organizacionais, a disposição das pessoas para compartilhar seus conhecimentos desempenha um papel importante na capacidade empresarial, a qual é explicada pelo processo de transferência de conhecimentos entre os trabalhadores, o que contribui para a implementação de novas ideias, processos, produtos ou serviços (MARTINEZ; GALVAN; PALACIOS, 2016).

Ao relacionar a transferência de conhecimentos com a capacidade absortiva, Chauvet e Guiot (2002), embasados por Zahra e George (2002), apontam quatro dimensões da capacidade absortiva, a qual, basicamente tem a função de valorar informações externas, assimilá-las e aplicá-las a fins organizacionais. As dimensões da capacidade absortiva incluem a aquisição, assimilação, transformação e exploração, destacando o processo de criação de conhecimento (TAKEUCHI; NONAKA, 2008) como central para a obtenção de vantagem estratégica. A aquisição, segundo os referidos autores, diz respeito à capacidade de reconhecer e valorizar conhecimentos externos, enquanto a assimilação refere-se à capacidade de analisar, processar, interpretar e compreender tal conhecimento. A transformação ocorre a partir da internalização do conhecimento para, posteriormente, na dimensão de exploração, aplicar os novos conhecimentos apreendidos para fins organizacionais. Engelman et al. (2017) argumentam que os ativos intangíveis são mobilizados pelas organizações por meio de recursos dinâmicos como a capacidade absortiva, sendo a inovação um dos resultados deste processo. Nesse sentido, os autores apontam que aquisição e a exploração do conhecimento têm uma influência intensa na inovação.

Chauvet e Guiot (2002) ressaltam que a capacidade absortiva pode ser útil para a organização se esta tiver uma boa propensão à transferência de conhecimento. Assim, é possível renovar constantemente o conhecimento, permitindo uma crescente flexibilidade estratégica da organização. Neste contexto, Rossetto et al. (2017) observam que a necessidade de maximizar a produtividade e reduzir custos faz com que as organizações invistam em transferência de conhecimento e capacidade de absorção.

Takeuchi e Nonaka (2008) observam que o papel das organizações no processo de transferência do conhecimento organizacional é promover o contexto apropriado para facilitar as atividades de grupo, assim como a criação e o acúmulo de conhecimentos em nível individual. Assim, supõe-se que o conhecimento não existe apenas na cognição de uma 
pessoa, mas sim precisa de um espaço para ser criado, o qual é específico ao contexto em termos de tempo e espaço. Deste modo, Nonaka e Konno (1998) afirmam que o conceito de $B A$ foi proposto originalmente por Kitaro Nishida e posteriormente adaptado por Takeuchi e Nonaka (2008) a fim de elaborar o modelo Seci. BA pode ser definido como um espaço compartilhado e dinâmico, no qual o conhecimento é criado e utilizado (NONAKA; KONNO, 1998). Os autores afirmam que o conhecimento está introduzido em tais espaços compartilhados e este, quando separado de $B A$, torna-se informação. Existe uma linha tênue entre o que é transferido: seja informação ou conhecimento. A informação torna-se conhecida quando é processada na mente de um indivíduo (conhecimento tácito) e retorna à informação (conhecimento explícito) por meio de práticas de articulação do conhecimento (AYRES; POPADIUK, 2016).

Neste contexto, Frank, Ribeiro e Echeveste (2011) observam que entre as características da organização que podem influenciar na capacidade de transferir conhecimentos destacam-se o tamanho da organização, suas estratégias e recursos disponíveis. Isto determina aspectos como as políticas gerais da organização em relação ao capital humano, salários e incentivos, que podem levar à perda ou vazamento de conhecimento se o incentivo às pessoas para permanecer na organização não for o suficiente.

Observa-se que o processo de globalização transformou o âmbito do trabalho por meio das inovações tecnológicas, as quais estão contribuindo para que exista, constantemente, uma redefinição de relações. Para Barros e Muniz (2014), as organizações estão cada vez mais exigentes e consoantes com o sistema capitalista na acumulação de capital. Assim, há elevação do ritmo de trabalho, do aumento das jornadas de trabalho e da polivalência dos trabalhadores. Du, Ai e Ren (2007) apontam que as características sociais e econômicas influenciam a transferência de conhecimentos, visto que estas definem o nível de educação e as características culturais do quadro de pessoal, o tipo de capacitação requerida para as pessoas e a própria capacidade de integração entre elas. Deste modo, é possível observar que a precarização do trabalho no Brasil pode ser considerada um dos fatores determinantes das dificuldades de se concretizar a transferência do conhecimento e a memória organizacional, uma vez que, entre outros fatores, tal precarização gera como consequência uma precariedade também nas relações estabelecidas nas organizações. Boas relações de trabalho são indispensáveis para a ocorrência da transferência de conhecimentos.

Entretanto, o compartilhamento do conhecimento tácito dos trabalhadores em fase de aposentadoria torna-se mais significativo do que nunca para o processo de inovação nas organizações, permitindo contribuições de diferentes gerações (SOUTO, 2014; GERPOTT; WILLENBROCK; VOELPEL, 2017). Os trabalhadores que sucedem aqueles que se afastaram do trabalho tendem a descobrir tarde demais a falta que o compartilhamento de conhecimentos pode fazer. Geralmente, os sucessores percebem tal falta por meio de equívocos ou problemas inesperados que poderiam ser evitados caso o compartilhamento de conhecimentos ocorresse (SOUTO, 2014).

Alguns dos benefícios resultantes do gerenciamento e retenção de conhecimento incluem otimizar a eficiência operacional, incentivar a inovação e possibilitar a busca de estratégias de crescimento (CALDAS et al., 2014). Nesse sentido, observa-se o estudo de Guerrazzi e Serra (2017) sobre o declínio em pequenas organizações. Os autores afirmam que o declínio ocorre devido à fatores internos e externos. Os fatores internos estão relacionados à exploração, prospecção de recursos e governança, principalmente em aspectos de aprendizagem e tomada de decisões. Por outro lado, os fatores externos são aqueles que implicam em uma transação entre a empresa e o meio ambiente. Segundo os autores, as dimensões internas, se bem resolvidas, levam ao equacionamento das ameaças externas. Dentre os aspectos internos, destacam-se aprendizagem contínua para minimização de riscos, definição de estratégias e de metas, percepção de riscos e gestão eficiente de recursos.

Perspectivas em Gestão \& Conhecimento, João Pessoa, v. 11, n. 1, p. 2-23, jan./abr. 2021. 
Em estudo que abordou as estratégias de retenção de conhecimentos em dois principais bancos sul-africanos, observou-se que a saída de trabalhadores aposentados apresentou desafios onde o conhecimento não foi compartilhado para outros trabalhadores, culminando em vazios que dificultaram a inovação (CHIGADA; NGULUBE, 2016). Ainda, em estudo em empresas familiares, Martinez, Galvan e Palacios (2016) apontam que a transferência de conhecimentos apresenta um efeito positivo e significativo na orientação empreendedora, o qual é influenciado pelas interações familiares. Neste sentido, os autores afirmam que os proprietários são a chave para a criação de conhecimento, visto que são eles quem impulsionam os processos de gerenciamento de conhecimento.

Por fim, ressalta-se a relevância em abordar a transferência de conhecimento de trabalhadores em fase de aposentadoria como uma prática empreendedora, uma vez que o não compartilhamento de conhecimentos de trabalhadores em fase de aposentadoria inclui não apenas a redução da capacidade inovadora, mas também o aumento da vulnerabilidade e os custos elevados e ocultos da reconstrução do conhecimento para as organizações (CALDAS et al., 2014).

\section{EMPREENDER POR MEIO DA TRANSFERÊNCIA DE CONHECIMENTOS}

A pesquisa acadêmica em empreendedorismo tem crescido durante as últimas três décadas, em parte aplicando teorias de outras áreas, e em parte desenvolvendo seu próprio campo de estudo. Porém, apesar do crescente interesse pelo empreendedorismo, a temática, enquanto campo acadêmico, ainda recebe críticas e questionamentos em relação a real existência de uma área específica de empreendedorismo que a diferencie de outros estudos na área da administração (FERREIRA; PINTO; MIRANDA, 2015). Adicionalmente, ainda há dificuldade no estabelecimento de definições mais precisas e universais para o empreendedorismo, o que reforça a necessidade de mais pesquisas sobre o tema (LANDSTRÖM; HARIRCHI; ASTRÖM, 2012; BARROS; PINTO; CASTRO, 2014; BACELAR; TEIXEIRA, 2016). Portanto, ainda que não seja evidente uma teoria própria de empreendedorismo, há um espaço amplo sobre o qual a pesquisa futura pode se desenvolver, propondo conceitos e teorias (FERREIRA; PINTO; MIRANDA, 2015). Borges et al. (2016) sugerem que é necessário esforço por parte dos pesquisadores ao explorar perspectivas ainda pouco estudadas na área do empreendedorismo, como a criação de novos negócios, processo empreendedor, aprendizagem, cultura organizacional e os diferentes tipos de empreendedorismo. Neste caso tem-se como foco o intraempreendedorismo, um dos diferentes tipos de empreendedorismo.

Semelhante ao empreendedorismo, o qual diz respeito a capacidade de inovar e criar valor, sustentando a ideia de empregar recursos disponíveis, assumir riscos calculados e promover as mudanças necessárias para o crescimento (DORNELAS, 2005), encontra-se o intraempreendedorismo. Empreendedores e intraempreendedores ao desenvolverem suas competências atribuem potencialidades ao mercado (NASSIF; ANDREASSI; SIMÕES, 2011). Neste texto segue-se a lógica dos autores quando afirmam que o intraempreendedorismo é visto como uma das formas de empreendedorismo corporativo em organizações existentes. Portanto, como referem Munhoz e Nassif (2012), o intraempreendedor transforma uma ideia em realidade na própria organização em que trabalha, não medindo esforços para fazer o que é preciso ser feito para alcançar os melhores resultados. Nessa lógica, Lapolli e Gomes (2017) destacam a importância da ocorrência de boas práticas organizacionais (autonomia, boa comunicação, tolerância à erros, etc) que possibilitam o intraempreendedorismo.

Para Dornelas (2005), os empreendedores são pessoas diferenciadas, visto que não se limitam as atividades cotidianas e buscam a inovação na execução das tarefas. Neste sentido, o conhecimento é percebido como um diferencial para a inovação, devido ao seu dinamismo e renovação constante (TAKEUCHI; NONAKA, 2008; CASTRO; GUIMARÃES; DINIZ, 2013).

Perspectivas em Gestão \& Conhecimento, João Pessoa, v. 11, n. 1, p. 2-23, jan./abr. 2021. 
Ressalta-se, portanto, que na atual era do conhecimento, onde a informação é transmitida de forma acelerada, as organizações necessitam criar estratégias para se desenvolverem e se manterem no contexto em que estão inseridas. Assim, percebe-se que a inovação é também, juntamente com o conhecimento, uma das respostas para essa problemática, visto que por meio dela é possível oportunizar o desenvolvimento organizacional (TAKEUCHI; NONAKA, 2008; LOPES et al., 2016). Observa-se que a inovação não está vinculada a somente um tipo de tecnologia, mas sim, está associada a utilização dos mais variados recursos oferecidos pelo conhecimento (TIDD; BESSANT; PAVITT, 2008). Neste sentido, o conhecimento, quando bem aproveitado, proporciona benefícios para as organizações e atua como um importante recurso estratégico. Por meio da transferência de conhecimentos é possível, por exemplo, contribuir para a criação de novas ideias, desenvolver produtos e reduzir custos maximizando a eficiência nos processos (COHEN; LEVINTHAL, 1990; VAN WIJK; JANSEN; LYLES, 2008; MARCANTE et al., 2015).

Porém, em contrapartida, não existem muitos autores que abordam o conhecimento como recurso estratégico das organizações para adoção de práticas empreendedoras (MARCANTE et al., 2015), ressaltando a importância de mais estudos na área, envolvendo também a GP. Ao buscar conhecer o campo de debate entre empreendedorismo e conhecimento no período e 2013 a 2018, observa-se crescimento na quantidade de estudos internacionais que fazem tal relação, porém, o debate nacional ainda é incipiente, conforme pode ser visualizado na Tabela 1. Os resultados são demonstrados com base em pesquisa realizada nos títulos, resumos e palavras-chaves das bases de dados Sage, Scielo, Scopus e Spell, buscando a relação entre empreendedorismo e conhecimento, em língua portuguesa e inglesa (knowledge and entrepreneurship), no período de 2013 a 2018, a fim de contemplar de forma ampla estudos recentes que relacionem tais temáticas. Foi utilizado o operador and, a fim de contemplar apenas estudos que relacionassem as duas temáticas. Inicialmente buscouse estudos sem limitação de área, para posteriormente reduzir a pesquisa aos estudos voltados à área das Ciências Sociais Aplicadas e, por fim, buscou-se estudos nacionais na área das Ciências Sociais Aplicadas.

Tabela 1 - Estudos que relacionam empreendedorismo e conhecimento: pesquisas no período de 2013 a 2018

\begin{tabular}{cccc}
\hline $\begin{array}{c}\text { Base de } \\
\text { Dados }\end{array}$ & $\begin{array}{c}\text { Número total } \\
\text { de Documentos }\end{array}$ & $\begin{array}{c}\text { Número de documentos na área } \\
\text { de Ciências Sociais Aplicadas }\end{array}$ & $\begin{array}{c}\text { Número de publicações nacionais } \\
\text { na área de Ciências Sociais } \\
\text { Aplicadas }\end{array}$ \\
\hline $\begin{array}{c}\text { Sage } \\
\text { Scielo }\end{array}$ & 178 & 15 & - \\
Scopus & 65 & 43 & 9 \\
Spell & 3.009 & 1.879 & 42 \\
Total & 3.252 & - & - \\
\hline
\end{tabular}

Fonte: as autoras (2019)

A partir dos dados apresentados, observa-se crescimento na quantidade de estudos que relacionam empreendedorismo com conhecimento, porém ressalta-se a necessidade de ampliar o campo de estudo na área das Ciências Sociais Aplicadas, principalmente no âmbito nacional. Por outro lado, observa-se que os estudos apresentados destacam apenas um panorama geral do campo de pesquisa entre empreendedorismo e conhecimento, sem contemplar uma análise aprofundada que aponte de que forma o conhecimento está sendo abordado em tais estudos. Assim, apesar do crescimento na quantidade de estudos voltados à relação entre empreendedorismo e conhecimento, dentre todos os estudos encontrados, há 
um número ainda menor que de fato relacionam o empreendedorismo com a transferência de conhecimento.

Dentre tais pesquisas, destacam-se os estudos como o de Dey (2017), o qual aponta que o conhecimento é sim um importante recurso estratégico para as organizações no que diz respeito ao empreendedorismo, uma vez que em um mundo intensivo em conhecimento, as suas vantagens e benefícios para as organizações são vistas como diferenciais para a competitividade. Neste contexto, ainda mais diante das mudanças demográficas no Brasil, fazse necessário também um novo olhar aos trabalhadores em fase de aposentadoria, uma vez que desenvolver as habilidades e o conhecimento destes é também um importante caminho para o crescimento organizacional (THÜRMER; YEDYENYOVA; SPIEB, 2017). Segundo Dey (2017), a capacidade de aprender e a capacidade de estabelecer um processo abrangente de aprendizagem organizacional são fatores determinantes para o empreendedorismo. Por meio da transferência de conhecimentos, as equipes, unidades ou organizações trocam e recebem conhecimentos, bem como são influenciados pela experiência e conhecimento dos demais (ARGOTE; INGRAM, 2000; LIAO; HU, 2007; VAN WIJK; JANSEN; LYLES, 2008; KUMAR; GANESH, 2009).

Em sentido semelhante, Lopes et al. (2016) afirmam que os elementos essenciais para o processo de inovação nas organizações são relacionados ao conhecimento, a criatividade e ao empreendedorismo. Portanto, a busca contínua pelo conhecimento oportuniza o desenvolvimento das organizações. Observa-se ainda que, nas micro e pequenas empresas, os procedimentos existentes e boa parte do conhecimento estão registrados apenas nas mentes das pessoas e não em sistemas que facilitem o desenvolvimento dos processos.

Nascimento e Vitoriano (2017) apontam que há uma construção de sentido de dados e informações por meio da memória organizacional, de modo a transformar algo estático em subsídios à estratégia da organização. Porém, os autores ressaltam que para que a organização possa usufruir da memória organizacional é preciso inicialmente trabalhar com a gestão documental e a gestão da informação, de modo a transformá-la numa ferramenta para a gestão do conhecimento. Deste modo, registrar o conhecimento dos trabalhadores por meio de procedimentos e manuais é uma das formas de preservar a memória organizacional, especialmente quando se trata de conhecimento explícito. Neste contexto, Tonini (2012) afirma que a escolha de ferramentas tecnológicas adequadas para captar, acessar e distribuir conhecimentos é essencial, especialmente ao tratar-se de conhecimento explícito. 0 referido autor exemplifica algumas das tecnologias mais aplicadas para este fim, tais como Gestão do Conteúdo ou Enterprise Content Management e Gestão Eletrônica de Documentos. Ambas as ferramentas permitem que as pessoas capturem, codifiquem e organizem suas experiências em servidores centrais possibilitando que toda a organização acesse as informações:

A Gestão Eletrônica de Documentos é definida como um somatório de todas as tecnologias e produtos que visam a gerenciar, de forma eletrônica, o ciclo de vida das informações desde a sua criação até o seu arquivamento. A informação pode estar na forma de texto, planilhas eletrônicas, som, imagens e outros. [...] O Enterprise Content Management ou gerenciamento do conteúdo é o gerenciamento de informações focando a captação, ajustes, distribuição e gerenciamento dos conteúdos para apoio processo de negócios de toda a empresa. A característica básica de um sistema de Enterprise Content Management é a disponibilização do acesso aos conteúdos da empresa através de uma interface única. (TONINI, 2012, p.7).

Segundo Nonato e Perez (2018), alguns sistemas de informação existentes nas organizações podem prover apoio à memória organizacional. Porém, a diversidade de sistemas

Perspectivas em Gestão \& Conhecimento, João Pessoa, v. 11, n. 1, p. 2-23, jan./abr. 2021. 
e a dependência do fator humano na captura e atualização das informações impõe limites a este apoio. Nascimento e Vitoriano (2017) afirmam que quando informação e conhecimento estão apenas armazenados em repositório e não são utilizados, eles retornam à condição de dados. Nonato e Perez (2018) apontam que os sistemas de informação podem contribuir para a memória organizacional ao permitir a retenção de conhecimento explícito, ao agregar impessoalidade ao processo de busca e recuperação, bem como ao identificar conhecimentos irrelevantes ou ainda obsoletos. Porém, ao se tratar de conhecimento tácito, é indispensável a socialização entre os trabalhadores, para que este seja transferido, uma vez que o aprendizado ocorre por meio da observação, da imitação, da prática e da experiência, sendo assim necessária empatia social, uma vez que as informações farão pouco sentido se forem dissociadas das emoções e dos seus contextos (NONAKA; TAKEUCHI, 2003). Assim, as organizações se tornam ainda mais reféns das pessoas, reforçando novamente a importância da transferência de conhecimentos entre trabalhadores, os quais podem contribuir com o desenvolvimento organizacional por meio das suas experiências e conhecimentos (MARCANTE et at., 2015).

Takeuchi e Nonaka (2008) observam que as organizações não podem criar conhecimento sozinhas, sem os indivíduos. Deste modo, apoiar e incentivar ações voltadas à criação e transferência de conhecimentos é essencial e traz benefícios em diversos âmbitos. Assim, cabe às organizações identificar suas limitações e potencialidades do ponto de vista organizacional e individual para manterem-se competitivas (GOMES et al., 2015). Em organizações com fortes lideranças, por exemplo, as práticas de GP visam estabelecer direcionamentos amplos e a formação de líderes que estejam atentos as pessoas. Assim, enquanto as práticas de GP auxiliam na criação de uma cultura organizacional geral que favoreça o comportamento empreendedor, é por meio de líderes preparados que as realizações efetivamente empreendedoras surgem nas organizações (FRANCO; PACHECO; HASHIMOTO, 2014).

Diante do exposto, ressalta-se que o conhecimento é o bem mais valioso de uma organização, sendo necessário atribuir atenção a ele para que a organização possa se desenvolver verdadeiramente (MARCANTE et at., 2015). Por meio da troca de conhecimentos é possível alcançar resultados mais efetivos para as organizações e para os trabalhadores, o que pode ser visto como um diferencial que viabiliza a inovação e a continuidade dos negócios (SANTOS; VALENTIM, 2014). É nessa lógica que fica evidenciada a importância da transferência de conhecimentos nas organizações, envolvendo, sobretudo, os trabalhadores com maior experiência, os quais estão próximos ou já estão em fase de aposentadoria, aproveitando assim a experiência e o conhecimento acumulado ao longo dos anos (SOUTO, 2014), o que minimiza a perda da memória organizacional. Dessa forma, como salientam Kim e Ko (2014) a transferência de conhecimentos entre os trabalhadores deve ser pensada antes que o processo da aposentadoria seja finalizado de fato, ainda mais que, como bem pontuam Colet, Mozzato e Bitencourt (2017), a troca intergeracional é importante tanto para os profissionais envolvidos (independentemente de geração), quanto para a organização.

\section{CONSIDERAÇÕES FINAIS}

Chegando ao final desta revisão entende-se que o objetivo proposto inicialmente quanto a debater sobre a relevância em abordar a transferência de conhecimento de trabalhadores em fase de aposentadoria como uma possível prática empreendedora foi alcançado, por mais que não esgotado. Observa-se que, apesar do crescimento nos estudos internacionais que relacionam conhecimento e empreendedorismo, o debate nacional ainda é incipiente, reforçando a necessidade de mais pesquisas.

Perspectivas em Gestão \& Conhecimento, João Pessoa, v. 11, n. 1, p. 2-23, jan./abr. 2021. 
Faz-se necessário pensar continuamente em novas estratégias de desenvolvimento organizacional em um contexto repleto de dinamismo, desafios e mudanças. Como bem pontuam Gomes et al. (2015), um dos objetivos do empreendedorismo é justamente compreender a relação entre a organização e o ambiente ao qual está inserida e, assim, aprender na interação com o ambiente externo e nos relacionamentos internos, favorecendo a construção de uma cultura organizacional empreendedora. Para tanto, mudanças internas são imprescindíveis, estando estas adjacentes ao processo da capacitação contínua e desenvolvimento profissional e organizacional.

O conhecimento surge como uma proposta para enfrentar os desafios organizacionais em um contexto que aponta para o crescente envelhecimento populacional, o qual traz desafios para a GP. Os conhecimentos e experiências dos trabalhadores em fase de aposentadoria são fundamentais para as organizações e difíceis de serem reconstruídos. Assim, como pontuam Caldas et al. (2014), por meio da valorização do conhecimento dos trabalhadores em fase de aposentadoria, benefícios como o aumento da eficiência operacional, o incentivo a inovação e a possibilidade de busca de estratégias de crescimento também são ressaltados.

Ainda, por meio da transferência de conhecimentos dos trabalhadores em fase de aposentadoria, as lideranças podem criar um ambiente de trabalho que aproveite as mudanças existentes no âmbito organizacional para promover o crescimento organizacional, uma vez que a partilha do conhecimento tácito dos trabalhadores em fase de aposentadoria é uma estratégia de intraempreendedorismo que visa minimizar os custos tangíveis e intangíveis de perder oportunidades de inovação. Quanto menos o conhecimento tácito dos trabalhadores ainda não aposentados for compartilhado, as oportunidades para se beneficiar desse conhecimento irão diminuir, empobrecendo a criação de novos conhecimentos.

É importante destacar que algumas organizações têm como cultura organizacional incentivar e encorajar a transferência do conhecimento, enquanto outras desencorajam esse processo. Portanto, seguindo o planejamento estratégico organizacional, é essencial que as lideranças incentivem o perfil empreendedor, a criatividade e a inovação, bem como proporcionem espaços que oportunizem a transferência de conhecimentos. Só dessa maneira que os trabalhadores poderão aprender com os conhecimentos e experiências daqueles que estão se desvinculando do trabalho. Para tanto, é indispensável que os espaços de compartilhamento de conhecimento com ênfase no empreendedorismo sejam valorizados e incentivados. Ao incentivar, por meio da educação contínua, o empreendedorismo e a transferência de conhecimento de trabalhadores em fase de aposentadoria, trabalhadores de todas as idades podem aprender novos conhecimentos e experiências e, como bem pontuam Marcante et al. (2015), quando bem aproveitado, o conhecimento é visto nas organizações como um excelente recurso estratégico. Tal conhecimento é dotado de um diferencial capaz de reduzir custos, tornar os processos mais eficientes, gerar lucro e reconhecer pequenos negócios tanto pela melhoria dos processos quanto pela adoção de práticas intraempreendedoras.

Por fim, observa-se que o questionamento proposto no título deste ensaio teórico tem sua resposta afirmativa, pois sim, a transferência de conhecimento de trabalhadores em fase de aposentadoria pode ser vista como uma prática empreendedora que pode resultar em desenvolvimento organizacional e uma das formas de as organizações permanecerem e se destacarem onde estão inseridas, mesmo que mais pesquisas sejam necessárias. Assim, tornase pertinente incentivar estudos que abordem a transferência de conhecimento de trabalhadores em fase de aposentadoria como uma prática empreendedora, tendo como foco o intraempreendedorismo, uma vez que esta possibilita a constante criação de conhecimento e inovação nas organizações, minimizando a perda da memória organizacional.

Perspectivas em Gestão \& Conhecimento, João Pessoa, v. 11, n. 1, p. 2-23, jan./abr. 2021. 


\section{REFERÊNCIAS}

ANTUNES, M. H.; SOARES, D. H. P.; SILVA, N. Orientação para aposentadoria nas organizações: histórico, gestão de pessoas e indicadores para uma possível associação com a gestão do conhecimento. Perspectivas em Gestão \& Conhecimento, v. 5, n. 1, p. 43-63, 2015. Disponível em: https://dialnet.unirioja.es/servlet/articulo?codigo=5112317. Acesso em: 20 jan. 2019.

ARAÚJO, D. L. A.; POPADIUK, S. Barreiras Inerentes a Transferência de Conhecimento: Um Estudo sob a Perspectiva de Franqueados do Segmento de Escolas de Idiomas. Revista Organizações em Contexto, v. 11, n. 21, p. 241-278, 2015. Disponível em: https://www.metodista.br/revistas/revistas-metodista/index.php/OC/article/view/5146.

Acesso em: 10 out. 2018.

ARGOTE, L.; INGRAM, P.; Knowledge Transfer: A Basis for competitive and advantage in firms. Organizational Behavior and Human Decision Processes, v. 82, n. 1, p. 150-169, 2000. Disponível em: http://citeseerx.ist.psu.edu/viewdoc/summary?doi=10.1.1.578.7807. Acesso em: 10 out. 2018.

ASHWORTH, M. J. Preserving knowledge legacies: workforce aging, turnover and human resource issues in the US electric power industry. The International Journal of Human Resource Management, v. 17, n. 9, p. 1659-1688, 2006.

AYRES, R. M. S. M.; POPADIUK, S. Knowledge transfer, learning and organizational capabilities in an inter-organizational software project. Organizações \& Sociedade, v. 23, n. 79, p. 553-570, 2016. Disponível em: http://www.scielo.br/scielo.php?pid=S198492302016000400553\&script=sci abstract\&tlng=pt. Acesso em: 20 jan. 2019.

BACELAR, S.D.; TEIXEIRA, R. M. Produção científica sobre empreendedorismo no brasil: estudo bibliométrico das publicações em periódicos e eventos entre 2008 e 2014. In: IX EGEPE Encontro de Estudos sobre Empreendedorismo e Pequenas Empresas, Anais... UPF, Passo Fundo, 2016. Disponível em: https://www.egepe.org.br/2016/artigos-egepe/095.pdf. Acesso em: 15 fev. 2019.

BARROS, A.; MUNIZ, T. S. M. O trabalhador idoso no mercado de trabalho do capitalismo contemporâneo. Caderno de Graduação Ciências Humanas e Sociais, v. 2, n. 1, p. 103-116, 2014.

BARROS, G. V. E.; PINTO, F. I. P.; CASTRO, V. T. Empreendedorismo na base da pirâmide: um estudo de caso em uma comunidade recém-pacificada. In: VIII EGEPE - Encontro de Estudos sobre Empreendedorismo e Pequenas Empresas. Anais... Goiania, 2014.

BLEICH, M. R.; CLEARY, B. L.; DAVIS, K.; HATCHER, B. J.; HEWLETT, P. O.; HILL, K. S. Mitigating knowledge loss: a strategic imperative for nurse leaders. The Journal of Nursing Administration, v. 45, n. 10, p. 16-20, 2015.

BONINI, L. A.; SBRAGIA, R. O modelo de design thinking como indutor da inovação nas empresas: um estudo empírico. Revista de Gestão e Projetos, v. 2, n. 1, p. 3-25, 2011.

Perspectivas em Gestão \& Conhecimento, João Pessoa, v. 11, n. 1, p. 2-23, jan./abr. 2021. 
Disponível em: http://www.revistagep.org/ojs/index.php/gep/article/view/36. Acesso em: 8 dez. 2018.

BORGES, A. F.; BRITO, M. J.; LIMA, J. B.; CASTRO, C. L. C. Empreendedorismo em empresas familiares: a pesquisa atual e os desafios futuros. Revista de Administração Mackenzie, São Paulo, v. 17, n. 2, p. 93-121, 2016. Disponível em: http://www.scielo.br/scielo.php?pid=S167869712016000200093\&script=sci abstract\&tlng=es. Acesso em: 15 fev. 2019.

CAHA, V.; MILETIĆ, Z.; PERIĆ, S.; RALJEVIĆ, D. Live work training centres cooperation and development. In: INTERNATIONAL CONFERENCE ON LIVE MAINTENANCE, 12, 2017. Anais... France: IEEE, 2017.

CALDAS, C. H.; ELKINGTON, R. W.; O'CONNOR, J. T.; KIM, J. Y. Development of a method to retain experiential knowledge in capital projects organizations. Journal of Management in Engineering, v. 31, n. 5, p. 04014083, 2014.

CALO, T. J. Talent management in the era of the aging workforce: the critical role of knowledge transfer. Public Personnel Management, v. 37, n. 4, p. 403-416, 2008.

CAMARANO, A. A. O idoso brasileiro no mercado de trabalho. Brasília: IPEA - Instituto de Pesquisa Econômica Aplicada, 2001, 27 p. (Texto para discussão, n. 830/2001). Disponível em: http://www.ipea.gov.br/portal/images/stories/PDFs/TDs/td 0830.pdf. Acesso em: 25 nov. 2018.

CASTRO, J.; GUIMARAES, L. O.; DINIZ, D. M. O papel dos fatores do contexto relacional na transferência de conhecimento tecnológico: um estudo de caso em uma organização pública de pesquisa agropecuária. Tourism \& Management Studies, v. 9, n. 2, p. 130-135, 2013. Disponível em: $\quad$ http://www.scielo.mec.pt/scielo.php?script=sci arttext\&pid=S218284582013000200019. Acesso em: 12 mar. 2019.

CHAUVET, V.; GUIOT, C. Absorptive capacity and knowledge transfer propensity: towards the obtaining of a competitive advantage. Organizational Behavior and Human Decision Processes, v. 82, n. 1, p. 150-159, 2002. Disponível em: https://pdfs.semanticscholar.org/b329/0334ea40cd7632541b716e43ba049f0a37b8.pdf.

Acesso em: 07 jul. 2019.

CHIGADA, J.; NGULUBE, P. A comparative analysis of knowledge retention strategies at selected banks in South Africa. Business Information Review, v. 33, n. 4, p. 221-227, 2016.

CHIRAWATTANAKIJ, S.; RACTHAM, V. V. Knowledge adoption: the influential factors in the process. Business Information Review, v. 32, n. 3, p. 158-167, 2015.

COHEN, W. M.; LEVINTHAL, D. A.; Absorptive capacity: a new perspective on learning and innovation. Administrative Science Quarterly, v. 35. p. 128 - 152, 1990. Disponível em: https://www.researchgate.net/profile/Daniel Levinthal/publication/220019726 Absorptive C apacity A New Perspective on Learning and Innovation/links/0fcfd5142b6a98e555000000. pdf. Acesso em: 12 mar. 2019.

Perspectivas em Gestão \& Conhecimento, João Pessoa, v. 11, n. 1, p. 2-23, jan./abr. 2021. 
COLET, D. S.; MOZZATO, A. R.; BITENCOURT, C. C. Gerações: afinal, é a nossa idade que nos define? In: SEMINÁRIO EM ADMINISTRAÇÃO - SEMEAD, 20, 2017. Anais... São Paulo: Semead, 2017.

DAVENPORT, T.; PRUSAK, L. Conhecimento empresarial: como as organizações gerenciam o seu capital intelectual. São Paulo: Futura, 2003.

DAWOUD, A. M.; STANDER, J.; HOSANI, S.; MAZROUEI, H.; ESTEVES, C.; HUSSEIN, T. Knowledge and experience transfer, an on the job training approach. In: INTERNATIONAL PETROLEUM EXHIBITION AND CONFERENCE, 2014. Anais... Abu Dhabi: Society of Petroleum Engineers, 2014.

DEY, A. K. Change management drivers: entrepreneurship and knowledge management. South Asian Journal of Business and Management Cases, v.6, n. 1, p. 7- 9, 2017.

DORNELAS, J. C. A. Empreendedorismo: transformando ideias em negócios. 2.ed. Rio de Janeiro: Campus, 2005.

DU, R.; Al, S.; REN, Y. Relationship between knowledge sharing and performance: a survey in Xi'an, China. Expert Systems with applications, v.32, p.38-46, 2007.

EKERDT, D. J. Frontiers of research on work and retirement. Journals of Gerontology Series B: Psychological Sciences and Social Sciences, v. 65, n. 1, p. 69-80, 2010. Disponível em: https://academic.oup.com/psychsocgerontology/article/65B/1/69/546549. Acesso em: 10 jun. 2019.

ENGELMAN, R. M.; FRACASSO, E. M.; SCHMIDT, S.; ZEN, A. C. Intellectual capital, absorptive capacity and product innovation. Management Decision, v. 55, n. 3, p. 474-490, 2017.

FERREIRA, M. P. V.; PINTO, C. F.; MIRANDA, R. M. Três décadas de pesquisa em empreendedorismo: uma revisão dos principais periódicos internacionais de empreendedorismo. Revista Eletrônica de Administração, Porto Alegre, v. 21, n. 2, p. 406436, $2015 . \quad$ Disponível em: http://www.scielo.br/scielo.php?pid=S141323112015000200406\&script=sci abstract\&tIng=es. Acesso em: 10 jun. 2019.

FRANÇA, L. H. F. P.; CARNEIRO, V. L. Programas de preparação para a aposentadoria: um estudo com trabalhadores mais velhos em Resende (RJ). Revista Brasileira de Geriatria e Gerontologia, v. 12, n. 3, p. 429-447, 2009. Disponível em: https://www.redalyc.org/pdf/4038/403838782010.pdf. Acesso em: 8 dez. 2018.

FRANÇA, L. H. F. P. Preparação para a aposentadoria: desafios a enfrentar. In: VERAS, R. (Org.). Terceira idade: alternativas para uma sociedade em transição, Rio de Janeiro: Relume Dumará/UnATI, 1999.

FRANÇA, L. H. F. P. Repensando a aposentadoria com qualidade: um manual para facilitadores de programas de educação para aposentadoria em comunidades. Rio de Janeiro: Universidade Aberta da Terceira Idade, 2002.

FRANÇA, L. H. F. P.; STEPANSKY, D. V. Educação permanente para trabalhadores idosos: o retorno à rede social. Boletim Técnico do Senac, v. 31, n. 2, p. 41-50, 2016.

Perspectivas em Gestão \& Conhecimento, João Pessoa, v. 11, n. 1, p. 2-23, jan./abr. 2021. 
FRANCO, M. M. S.; PACHECO, S.; HASHIMOTO, M. Liderança empreendedora e práticas de RH: um estudo sobre a eficácia na promoção do empreendedorismo corporativo. Revista de Empreendedorismo e Gestão de Pequenas Empresas, v. 3, n. 3, p. 104-128, 2014.

FRANK, A. G.; RIBEIRO, J. L. D.; ECHEVESTE, M. E. S. Uma análise dos fatores de influência na transferência de conhecimentos entre projetos de produto. In: Congresso Brasileiro de Gestão de Desenvolvimento de Produto. Porto Alegre, RS. 2011.

GERPOTT, F. H.; WILLENBROCK, N. L.; VOELPEL, S. C. A phase model of intergenerational learning in organizations. Academy of Management Learning \& Education, v. 16, n. 2, p. 193216, 2017.

GOMES, R. K.; GOMES J. W. V.; LAPOLLI, E. M.; DANDOLINI, G. A. O empreendedorismo sob um enfoque sistêmico da organização. Revista ESPACIOS, v. 36, n. 18, p. 3, 2015. Disponível em: http://www.revistaespacios.com/a15v36n18/15361803.html. Acesso em: 20 jan. 2019.

GUERRAZZI, L. A. C.; SERRA, F. A. R. Declínio em pequenas empresas: abordagens e trabalhos relevantes. Revista Eletrônica de Administração, Porto Alegre, v. 23, n. 3, p. 206-238, 2017.

HAMILTON, E. Entrepreneurial learning in family businesses: a situated learning perspective. Journal of small business and enterprise development, v. 18, n.1, p. 8-26, 2011.

IBGE - Instituto brasileiro de geografia e estatística. Projeção da população do Brasil por sexo e idade para o período 1980-2050 - Revisão 2008. Rio de Janeiro: IBGE, 2008. Disponível em: www.ibge.org.br. Acesso em: 20 jan. 2018.

JESUS, A. M.; MOURÃO, L. Conhecimento organizacional em escolas de governo: um estudo comparado. Revista de Administração Pública, v. 46, n. 4, p. 939-968, 2012. Disponível em: http://bibliotecadigital.fgv.br/ojs/index.php/rap/article/view/7119. Acesso em: 12 mar. 2019.

KANG, M.; KIM, Y. G. A multilevel view on interpersonal knowledge transfer. Journal of the American Society for Information Science and Technology, v. 61, n. 3, 2010.

KNOETZE, S.; JANTJIES, M. Transferring knowledge to digital natives in a South African organization. In: Proceedings of the $\mathbf{2 0 1 9}$ the 5th International Conference on e-Society, eLearning and e-Technologies. ACM, 2019. p. 16-21.

KUMAR, J. A.; GANESH, L. S. Research on knowledge transfer in organizations: a morphology. Journal of Knowledge Management, v.13 n. 4, p. 161-174, 2009.

KIM, Y. W.; KO, J. HR practices and knowledge sharing behavior: Focusing on the moderating effect of trust in supervisor. Public Personnel Management, v. 43, n. 4, p. 586-607, 2014.

LANDSTRÖM, H.; HARIRCHI, G.; ASTRÖM, F. Entrepreneurship: exploring the knowledge base. Research Policy, v. 41. p. 1154-1181, 2012.

LAPOLLI, É.; GOMES, R. K. Práticas intraempreendedoras na gestão pública: um estudo de caso na Embrapa. Estudos Avançados, v. 31, n. 90, p. 127-142, 2017. 
LIAO, S.; HU, T. Knowledge transfer and competitive advantage on environmental uncertainty: an empirical study of the Taiwan semiconductor industry. Technovation, v. 27, n. 6-7, p. 402411, 2007.

LIYANAGE, C.; ELHAG, T.; BALLAL, T.; LI, Q. Knowledge communication and translation - a knowledge transfer model. Journal of Knowledge Management, v. 13, n. 3, p. 118-131, 2009.

LOPES, J. B.; OLIVEIRA, K. B.; SANTOS, A. P. S.; YAMAGUCHI, C. K. Elementos da inovação nas organizações. Revista ESPACIOS, v. 37, n. 13, p. 6, 2016. Disponível em: http://www.revistaespacios.com/a16v37n13/16371306.html. Acesso em: 10 mar. 2019.

LYLES, M. A.; EASTERBY-SMITH, M. E. Organizational learning and knowledge management: agendas for future research. In: EASTERBY-SMITH, M.; LYLES, M. (Org.). The Blackwell Handbook of organizational learning and knowledge management. London: Blackwell, 2003. p. 639-652.

MACÊDO, L. S. S.; BENDASSOLLI, P. F.; TORRES, T. de L. Representações sociais da aposentadoria e intenção de continuar trabalhando. Psicologia \& Sociedade, v. 29, p. 1-11, 2017.

MANSOUR, S.; TREMBLAY, D. G. What strategy of human resource management to retain older workers?. International Journal of Manpower, v. 40, n. 1, p. 135-153, 2019.

MARCANTE, C.; FACCIN, K.; RIBAS, F. T. T.; ZAN, T.; OLIBONI, B. F. A gestão do conhecimento como recurso estratégico para adoção de práticas empreendedoras. In: CONGRESSO DE PESQUISA E EXTENSÃO DA FACULDADE DA SERRA GAÚCHA, 3, 2015. Anais... Caxias do Sul: Congresso de Pesquisa e Extensão da FSG, 2015. Disponível em: http://ojs.fsg.br/index.php/pesquisaextensao/article/view/1604. Acesso em: 07 jun. 2019.

MARTENS, C. D. P.; LACERDA, F. M.; BELFORT, A. C.; FREITAS, H. M. R. D. Research on entrepreneurial orientation: current status and future agenda. International Journal of Entrepreneurial Behavior \& Research, v. 22, n. 4, p. 556-583, 2016.

MARTINEZ, A. B.; GALVAN, R. S.; PALACIOS, T. M. B. Entrepreneurial orientation and knowledge transfer: analysis in spanish family businesses. Tourism \& Management Studies, v. 12, n. 1, p. 211-219, 2016.2 Disponível em: http://www.scielo.mec.pt/scielo.php?script=sci arttext\&pid=S2182-84582016000100022.

Acesso em: 10 mar. 2019.

MUNARI, D. B.; BEZERRA, A. L. Q.; NOGUEIRA, A. L.; ROCHA, B. S.; SOUSA, E. T.; RIBEIRO, L. C. M. Sucessão de lideranças em enfermagem: pensar e agir hoje para garantir o amanhã. Revista Eletrônica de Enfermagem, v. 19, p. 1-4, 2017. Disponível em: https://www.revistas.ufg.br/fen/article/view/46101. Acesso em: 10 jun. 2019.

MUNHOZ, C. E.; NASSIF, V. M. J. O desvelar das competências dos intraempreendedores: um estudo exploratório em empresas de serviços. Revista Economia \& Gestão, v. 12, n. 30, p. 2048, 2012.

MURRAY, S. R.; PEYREFITTE, J. Knowledge type and communication media choice in the knowledge transfer process. Journal of Managerial Issues, v. 19, n. 1, p. 111-133, 2007.

Perspectivas em Gestão \& Conhecimento, João Pessoa, v. 11, n. 1, p. 2-23, jan./abr. 2021. 
NASCIMENTO, N. M.; VITORIANO, M. C. C. P. O estudo da produção documental e a memória organizacional em ambientes empresariais. Em Questão, v. 23, n. 1, p. 202-227, 2017.

NASSIF, V. M. J.; ANDREASSI, T.; SIMÕES, F. Competências empreendedoras: há diferenças entre empreendedores e intraempreendedores? RAI Revista de Administração e Inovação, v. 8, n. 3, p. 33-54, 2011.

NETO, E. C. C.; PERIN, M. G.; FERREIRA, G. C. Transferência de conhecimento: a perspectiva empresarial. Revista Gestão \& Tecnologia, v. 19, n. 2, p. 195-216, 2019. Disponível em: http://revistagt.fpl.edu.br/get/article/view/1503. Acesso em: 10 jun. 2019.

NONAKA, I.; KONNO, N. The concept of "Ba": building a foundation for knowledge creation. California Management Review, v. 40, n. 3, p. 40-54, Spring, 1998.

NONAKA, I.; TAKEUCHI, H. Criação de conhecimento na empresa: como as empresas japonesas geram a dinâmica da inovação. Rio de Janeiro: Campus, 2003.

NONATO, J. A. A.; PEREZ, G. Os Sistemas de Informação e seu Apoio às Funções da Memória Organizacional: um Estudo Exploratório. Information Systems and Techonology Management, São Paulo, v. 15, 2018.

RAU, B. L.; ADAMS, G. A. Aging, retirement, and human resources management: a strategic approach. In: WANG, M. (Ed.) The Oxford Handbook of Retirement. New York: Oxford Library of Psychology, 2013.

RIBEIRO, J. S. A. N.; CALIJORNE, M. A. S.; JURZA, P. H.; ZIVIANI, F.; NEVES, J. T. R. Gestão do conhecimento e desempenho organizacional: integração dinâmica entre competências e recursos. Perspectivas em Gestão \& Conhecimento, v. 7, n. 1, p. 4-17, 2017. Disponível em: https://dialnet.unirioja.es/servlet/articulo?codigo=5908258. Acesso em: 10 jun. 2019.

ROSSETto, B. A. CARVAlHo, F. C.; BeRnARDES, R.; BORINI, F. Absorptive Capacity and Innovation: An Overview of International Scientific Production of Last Twenty-Five Years. International Journal of Innovation, v. 5, n. 1, p. 97-113, 2017. Disponível em: https://papers.ssrn.com/sol3/papers.cfm?abstract id=2978188. Acesso em: 10 jun. 2019.

SANAKAM, S. R. Digital architecture, infrastructure and cultural development in the information age using 3D animated video manuals for attracting, engaging and enriching future workforce. In: INTERNATIONAL PETROLEUM EXHIBITION AND CONFERENCE, 30, 2014. Anais... Abu Dhabi: Society of Petroleum Engineers, 2014.

SANTOS, C. D.; VALENTIM, M. L. P. As interconexões entre a gestão da informação e a gestão do conhecimento para o gerenciamento dos fluxos organizacionais. Perspectivas em Gestão \& Conhecimento, v. 4, n. 2, p. 19-33, 2014 . Disponível em: https://repositorio.unesp.br/handle/11449/114790. Acesso em: 07 mar. 2019.

SANTOS, G. P.; PEREIRA, J. D. M.; LUCENA, S. Resenha: Fava, Rui. Trabalho, educação e inteligência artificial: a era do indivíduo versátil. Periferia, v. 11, n. 1, p. 325-330, 2019. Disponível em:

https://www.e-

Perspectivas em Gestão \& Conhecimento, João Pessoa, v. 11, n. 1, p. 2-23, jan./abr. 2021. 
publicacoes.uerj.br/index.php/periferia/article/viewFile/39598/28124. Acesso em: 07 jul. 2019.

SHULTZ, K. S.; HENKENS, K. Introduction to the changing nature of retirement: an international perspective. International Journal of Manpower, v. 31, n. 3, p. 265-270, 2010.

SILVA, J. R. G.; WETZEL, U.; LOPES, A. L. S. V. A visão de trabalhadores maduros com formação superior sobre sua condição no contexto das novas relações de trabalho no Brasil. In: ENCONTRO NACIONAL DA ANPAD, 32, 2008. Anais... Rio de Janeiro: Anpad, 2008.

SOUTO, P. C. N. Sharing experienced Baby Boomers' tacit knowledge: the design of tacit knowledge sense-making-sharing interactions. International Journal of Innovation and Learning, v. 15, n. 3, p. 299-327, 2014.

SUMBAL, M. S. U.; TSUI, E.; LEE, W. B. Baby boomers retirement in oil and gas-challenges of knowledge transfer for organizational competitive advantage. Community College Journal of Research and Practice, v. 40, n. 8, p. 695-705, 2015.

TAKEUCHI, H.; NONAKA, I. Teoria da criação do conhecimento organizacional. Gestão do conhecimento. Porto Alegre: Bookman, p. 54-90, 2008.

THÜRMER, J. L.; YEDYENYOVA, A.; SPIEB, E. Identifying barriers to continued training for older workers in a production plant: a mixed-methods approach. International Journal of Disability Management, v. 12, n. 1, p. 1-11, 2017.

TIDD, J.; BESSANT, J; PAVITT, K. Gestão da inovação. 3. Ed. Estado: Artmed, 2008.

TONINI, R. S. S. A memória organizacional integrada ao gerenciamento de projetos. In: VIII Congresso Nacional de Excelência em Gestão. Rio de Janeiro, RJ. 2012

VANZELLA, E. A.; LIMA NETO, E. A.; DA SILVA, C. C. A terceira idade e o mercado de trabalho. Revista Brasileira de Ciência da Saúde, v. 14, n. 4, p.97-100, 2011.

VAN WIJK, R.; JANSEN, J. J. P.; LYLES, M. A. Inter and intra organizational knowledge transfer: a meta-analytic review and assessment of its antecedents and consequences. Journal of Management Studies, v. 45, n. 4, p. 830-853, 2008.

ZANELLI, J. C. O programa de preparação para aposentadoria como um processo de intervenção ao final de uma carreira. Revista de Ciências Humanas, Edição Especial Temática, n. 4 p. 157-176, 2000. Disponível em: https://periodicos.ufsc.br/index.php/revistacfh/article/view/25796/22594. Acesso: $15 \mathrm{fev}$. 2019. 
ZAHRA, S. A.; GEORGE, G. Absorptive capacity: a review, reconceptualization, and extension. Academy of Management Review, v. 27, n. 2, p. 185-203, 2002.

ZAHRA, S. A. Organizational learning and entrepreneurship in family firms: exploring the moderating effect of ownership and cohesion. Small Business Economics, v. 38, n. 1, p. 51-65, 2012.

ZIMMER, M. V.; LEIS, R.P. Gestão do conhecimento no Brasil: o que está sendo produzido e para onde caminha a área. In: ANTONELLO, C. S.; GODOY, A. S. Aprendizagem organizacional no Brasil. Porto Alegre: Bookman, 2011. p. 160-182.

Recebido em/Received: 18/11/2019 | Aprovado em/Approved: 08/01/2021 